\title{
Opening the Door for Others
}

One second, I'm having the time of my life lead climbing up a wall with my 2 teenaged sons, the next I'm hanging upside down and in agony with what turns out to be a dislocated and fractured foot after falling 4 to $5 \mathrm{~m}$ down onto a rock ledge. Going from a highly active lifestyle to 3 months of almost complete inactivity and prolonged rehabilitation has been a sobering journey. It has also taught me a few valuable lessons about the challenges faced by those without full mobility and what it means to hold the door open for others.

The issue of accessibility comes into stark relief when on crutches, especially over the course of 2 weeks traveling throughout Europe for conferences. Getting on and off trains was literally a leap into the unknown due to wide platform gaps and narrow steep steps onto cars. I managed through the combination of sitting on my butt, pushing myself backward up the steps, and then hauling myself upward by my arms. How do you do this if you suffer from arthritis or otherwise lack sufficient strength? Elevators, when available at all, were tucked away in back corners, requiring a lot of extra travel for those who are already limited in mobility. In one of my hotels, the sole elevator was next to the kitchen's service entrance and required a tightly confined $90^{\circ}$ turn to enter-a turn that would be almost impossible in a wheelchair. It was also extremely narrow and small, such that most wheelchairs would never fit anyway. At one conference venue at a university, the building had no elevators at all.

The truth is that, in overt and covert ways, individuals with mobility issues face multiple additional hurdles that able-bodied individuals do not even remotely consider, let alone experience. On crutches, even moving a cup of coffee from the kitchen to the dining room involved a series of carefully planned movements and repositioning. These constant micro-obstacles add up to substantial additional physical and mental challenges for individuals with mobility issues. Even being otherwise fit and healthy, I found my world narrowing, with just the daily 500-m hobble from hotel to conference venue more than enough to leave me exhausted and with no desire to venture beyond.

Going through this journey struck home the need to hold the door open for others and ease their path as much as possible so that they can reach their potential. For the academics among us, what are the daily challenges faced by our trainees? What can we be doing to remove the brakes stopping them from focusing fully on their learning? Are we truly encouraging them to join us as emerging colleagues, or are we still maintaining barriers based on tradition or the perceived need for authority? Being in sport sciences, are we modeling and providing an environment that promotes a healthy work-life balance, ideally coupled with an active lifestyle?

For our friends and colleagues who are early career researchers, the academic world has also changed greatly. The pressures of publishing, getting grants, and committee work have only accelerated over my career. When mentoring younger colleagues, it's critical to appreciate this change in landscape and take the load off of them in terms of external demands like administrative duties. At the same time, we must facilitate opportunities for them to become leaders in their own right rather than retaining an "old boys club" mentality for senior leadership roles and board memberships.

For the athletes that we work with, what are the hidden challenges, obstacles, and pressures that they face? This is important for able-bodied athletes, but even more so for Paralympic athletes. Whether during training, recovery, travel, or competitions, it requires deep empathy and communication to see what obstaclesreal or imagined-may be holding them back from training or competing at their full capacity. This is doubly difficult because often the athletes themselves may not be aware of these obstacles, and many sport scientists have not walked the walk as elite athletes themselves.

In their groundbreaking research and book Nudge, ${ }^{1}$ Nobel economics laureate Richard Thaler and Cass Sunstein highlight the importance of the built environment in behavior and decision making, using smart design to remove barriers and guide individuals toward better or optimal behavior. I would argue that it is our duty to look at our academic and sport-science support environments and shape them toward optimal performance for those we work with and mentor.

Stephen S. Cheung, Associate Editor, IJSPP

\section{Reference}

1. Thaler RH, Sunstein CR. Nudge. New Haven, CT: Yale University Press; 2008. 